\title{
PROSPECÇÃO FITOQUÍMICA DE ADUBOS VERDES EM CULTIVO EXCLUSIVO E CONSORCIADO
}

Wellington Pereira de Carvalho ${ }^{1}$, Gabriel José de Carvalho ${ }^{2}$, Maria das Graças Cardoso ${ }^{3}$, Milene Aparecida Andrade ${ }^{4}$, Juliana de Andrade ${ }^{4}$, Maria Luisa Teixeira ${ }^{4}$, Lucilene Fernandes Silva ${ }^{4}$

\footnotetext{
${ }^{1}$ Pesquisador - Embrapa Cerrados, Planaltina (DF).

${ }^{2}$ Professor - Departamento de Agricultura, Universidade Federal de Lavras (MG).

${ }^{3}$ Professora - Departamento de Química, Universidade Federal de Lavras (MG).

${ }^{4}$ Graduanda - Departamento de Química, Universidade Federal de Lavras (MG).
}

RESUMO: A prospecção fitoquímica preliminar é o passo inicial na identificação dos principais grupos de metabólitos secundários aos quais pertencem substâncias alelopáticas, servindo de base para posterior análise cromatográfica. $\mathrm{O}$ objetivo neste trabalho foi realizar a triagem fitoquímica para identificação dos principais grupos de metabólitos primários e secundários presentes em adubos verdes utilizados como plantas de cobertura no controle de plantas infestantes. Foram obtidos 15 extratos etanólicos das leguminosas crotalária (Crotalaria anagyroides H.B.K.), feijão-de-porco (Canavalia ensiformis (L.) DC) e guandu (Cajanus cajan (L). Millsp) e das poáceas aveia-preta (Avena strigosa Schieb), sorgo (Sorghum bicolor (L.) Moench) e milheto (Pennisetum glaucum (L.) R. Brown), em cultivo exclusivo e consorciado. Com esses extratos, foram realizados os testes analíticos qualitativos utilizando reagentes específicos para a caracterização dos principais grupos de substâncias vegetais. Derivados de cumarinas e saponinas espumídicas são compostos encontrados nos resíduos de todas as espécies de adubos verdes estudadas, tanto em cultivo exclusivo, como em consórcio. Polissacarídeos e catequinas são compostos ausentes nos resíduos de todas as espécies de adubos verdes estudadas, tanto em cultivo exclusivo, como em consórcio.

Palavras-chave: Alelopatia. Leguminosae. Metabólitos secundários. Plantas de cobertura, Poaceae.

\section{GREEN MANURES PHYTOCHEMICAL SCREENING WITH AND WITHOUT INTERCROPPING}

\begin{abstract}
The preliminary phytochemical screening is the initial step in the identification of the main chemical groups of secondary metabolites in which belong allelopathic substances, serving as base for subsequent chromatographic analysis. This study aimed to characterize chemical groups of secondary metabolites present in green manures used as cover plants for weed control. Fifteen ethanolic extracts were obtained from leguminous species sunn hemp (Crotalaria anagyroides H.B.K.), jack beans (Canavalia ensiformis (L.) DC), pigeon pea (Cajanus cajan (L.) Millsp) and the grassy species black oat (Avena strigosa Schieb), sorghum (Sorghum bicolor (L.) Moench) and millet
\end{abstract}


(Pennisetum glaucum (L.) R. Brown), sown with and without intercropping. Qualitative analytical tests were performed with these extracts, using specific reagents for the characterization of the major groups of plant substances. Coumarins derivatives and saponins are found in residues of all studied species of green manure, with and without intercropping. Polysaccharides and catechins, are absent in the residues of all species of green manures studied, with and without intercropping.

Key words: Allelopathy. Cover crops. Leguminosae. Poaceae. Secondary metabolites.

\section{INTRODUÇÃO}

O cultivo de plantas para cobertura é excelente meio de promover a diversidade e estabilidade do sistema agrícola, pois os recursos disponíveis, como água, nutrientes e luz, entre outros, são utilizados de forma mais eficiente. Essas espécies propiciam o aumento da fertilidade do solo, além de protegê-lo contra erosão, aumentam seu teor de matéria orgânica e sua capacidade de troca de cátions (CTC), reduzem sua compactação, diminuem a perda de umidade, diminuem o ataque de pragas, além de atuar na supressão de plantas infestantes (CHERR et al., 2006). O controle da matovegetação ocorre pela competição por recursos disponíveis, promovendo condições que são desfavoráveis para sua germinação e estabelecimento (TEASDALE, 1998), e isso inclui a alelopatia, que é o efeito inibitório ou estimulativo de uma planta em outras espécies como resultado da liberação de substâncias químicas no ambiente, cuja origem pode ser tanto da planta viva, como de sua palha seca após o corte, que nesse caso, recebe o nome de cobertura morta (PUTNAM; TANG, 1986).

A vantagem da utilização de plantas da família das leguminosas como plantas de cobertura está relacionada ao fato de essas apresentarem potencial de produção de biomassa e à sua capacidade de fornecer nitrogênio à cultura sucessora (MATHEIS et al., 2006). Entretanto, são plantas com baixa relação carbono/nitrogênio $(\mathrm{C} / \mathrm{N})$, apresentando elevada velocidade de decomposição e liberação de nutrientes de seus resíduos. Por outro lado, as poáceas destacam-se pela capacidade de produzir biomassa, tendo resíduos com relação $\mathrm{C} / \mathrm{N}$ elevada, contribuindo para menor taxa de decomposição e liberação mais lenta de nutrientes para culturas. Além disso, a presença de uma espécie poácea como adubo verde é importante para a absorção de fósforo e potássio das camadas subsuperficiais, disponibilizando-os na superfície do solo (ROSSI et al., 2008).

O cultivo consorciado dessas espécies pode proporcionar benefícios à produção vegetal, visto que tais plantas apresentam características intrínsecas que resultam, por exemplo, na exploração de camadas distintas de solo, no favorecimento de grupos da biota do solo, na ciclagem diferenciada de nutrientes essenciais e na estruturação física do solo, além de proporcionar produção de matéria seca com relação $\mathrm{C} / \mathrm{N}$ intermediária, obtendo-se taxa de decomposição de resíduos culturais menor. Nesse contexto, investigar o desempenho de determinadas espécies consorciadas é de alta relevância.

O uso de plantas de cobertura como alternativa à aplicação de herbicidas no controle de plantas infestantes tem sido estudado, principalmente por aqueles que praticam 
agricultura sustentável. Dependendo da espécie de planta de cobertura e da quantidade de palhada existente sobre o solo, o controle das plantas daninhas pode ocorrer devido à liberação de compostos alelopáticos e/ou pelo efeito físico da palhada, associado com a ativação dos mecanismos de dormência ou com a formação de barreira física, impedindo a sobrevivência das sementes germinadas na superfície do solo (GOMES JUNIOR; CHRISTOFFOLETI, 2008).

De acordo com Putnam e Tang (1986), substâncias químicas com potencial alelopático estão presentes em quase todas as plantas e em muitos tecidos, como folhas, talos, flores, frutas, sementes e raízes. Sob condições específicas, essas substâncias químicas são liberadas no meio ambiente por meio de volatilização, lixiviação, decomposição de resíduos e exsudação de raízes (CHOU, 1999), em grandes quantidades e persistência longa para afetar uma planta vizinha ou sucessora. Esses processos também são afetados pelo complexo ambiental, e não é fácil separá-los (EINHELLIG, 1986).

A maioria dos produtos naturais que causam alelopatia são um subconjunto da ordem de compostos secundários sintetizados por plantas e micro-organismos, e a maioria dos compostos atualmente identificados são produtos das rotas do ácido chiquímico e do acetato (RICE, 1984). Os mais comuns incluem fenólicos, como cinâmico e ácidos benzoicos, cumarinas, taninos e flavonoides; terpenoides e alguns alcaloides, esteroides e quinonas (EINHELLING, 1985).

A identificação de substâncias moleculares em diferentes espécies de plantas tem contribuído para um conhecimento mais acurado de inúmeros compostos secundários, que podem ser agrupados de diversas formas. Muitos desses compostos são potencialmente aleloquímicos. Dos milhares de compostos naturais identificados a cada ano, que ocorrem nas plantas, nos micro-organismos e no solo, poucos têm sido estudados para seu uso potencial (FERREIRA; ÁQÜILA, 2000).

O estado atual do conhecimento sobre a ocorrência de alelopatia na adubação verde sugere que são amplas as possibilidades de se explorar esse fenômeno nos diferentes sistemas agrícolas, visando ao controle de plantas infestantes (AMABILE; CARVALHO, 2006). Para isso, estudos devem ser realizados com o objetivo de identificar substâncias químicas presentes em sua parte aérea usada como cobertura morta.

No presente trabalho, objetivou-se identificar alguns grupos de metabólitos primários e secundários presentes em três leguminosas e três poáceas, em cultivo exclusivo e consorciado, utilizadas como cobertura morta no período de entressafra.

\section{MATERIAL E MÉTODOS}

Para obtenção do material vegetal, foram preparados canteiros no campo experimental do Departamento de Agricultura da Universidade Federal de Lavras (UFLA), cuja altitude é de 919 metros, latitude de $21^{\circ} 14^{\prime}$ 'S e longitude de $45^{\circ} 00^{\prime}$ W GRW. De acordo com a classificação de Köppen, o clima da região é de transição entre Cwb e Cwa, com duas estações bem definidas, uma fria e seca, de abril a setembro e uma quente e úmida, de

Cultura Agronômica, Ilha Solteira, v.24, n.3, p.257-274, 2015 
outubro a março.

O solo onde foram instalados os canteiros é classificado como latossolo vermelho distroférrico (EMBRAPA, 2000) e apresentou na profundidade de $0-20 \mathrm{~cm}, \mathrm{pH}(\mathrm{H} 2 \mathrm{O})=$ 6,$0 ; \mathrm{Al}=0,1 \mathrm{cmol} / \mathrm{dm}^{3} ; \mathrm{P}=2,2 \mathrm{mg} / \mathrm{dm}^{3} ; \mathrm{K}=61,3 \mathrm{mg} / \mathrm{dm}^{3} ; \mathrm{Ca}=1,9 \mathrm{cmol} / \mathrm{dm}^{3} ; \mathrm{Mg}=0,8$ $\mathrm{cmol} / \mathrm{dm}^{3} ; \mathrm{H}+\mathrm{Al}=2,9 \mathrm{cmol} / \mathrm{dm}^{3} ; \mathrm{MO}=2 \mathrm{dag} / \mathrm{kg} ; \mathrm{Zn}=1,7 \mathrm{mg} / \mathrm{dm}^{3} ; \mathrm{Fe}=365,8 \mathrm{mg} / \mathrm{dm}^{3} ;$ $\mathrm{Mn}=45 \mathrm{mg} / \mathrm{dm}^{3} ; \mathrm{Cu}=3 \mathrm{mg} / \mathrm{dm}^{3} ; \mathrm{B}=0,2 \mathrm{mg} / \mathrm{dm}^{3} ; \mathrm{S}=9,1 \mathrm{mg} / \mathrm{dm}^{3}$; areia $=49 \%$; silte = $15,3 \%$ e argila $=35,7 \%$. Não foram feitas adubações de plantio e de cobertura.

Foram semeadas nos canteiros as leguminosas crotalária (Crotalaria anagyroides H.B.K.), feijão-de-porco (Canavalia ensiformis (L.) DC) e guandu (Cajanus cajan (L). Millsp) e as poáceas aveia-preta (Avena strigosa Schieb), sorgo (Sorghum bicolor (L.) Moench) e milheto (Pennisetum glaucum (L.) R. Brown). No total, foram obtidos 15 extratos provenientes da parte aérea das seis espécies que foram plantadas solteiras e consorciadas (crotalária, feijão-de-porco, guandu, aveia-preta, sorgo, milheto, crotalária + aveia-preta, crotalária + sorgo, crotalária + milheto, feijão-de-porco + aveia-preta, feijão-deporco + sorgo, feijão-de-porco + milheto, guandu + aveia-preta, guandu + sorgo e guandu + milheto).

O corte dos adubos verdes foi realizado quando $50 \%$ das plantas estavam na época da floração, retirando-se uma amostra de $1 \mathrm{~m} 2$ dentro da área útil de cada canteiro, no período da manhã do dia 21 de fevereiro de 2011. O dia estava seco e ensolarado. Após a coleta, o material foi limpo, acondicionado em sacos de papel e levado para secagem em estufa com circulação forçada à temperatura de $40^{\circ} \mathrm{C}$, até obter massa seca estável; em seguida, foi armazenado em câmara fria.

A abordagem fitoquímica para prospecção dos constituintes químicos presentes nos extratos de adubos verdes foi realizada no Laboratório de Química Orgânica da Universidade Federal de Lavras. Para a preparação dos extratos, o material foi picado em fragmentos de $1 \mathrm{~cm}$, com a finalidade de aumentar a superfície de contato durante o processo de extração. Pesaram-se 20 gramas de cada amostra, que foram colocadas em um balão de fundo redondo com capacidade para $500 \mathrm{~mL}$ e sobre elas, colocou-se etanol até atingir 2/3 da capacidade do balão, de modo a cobrir todo o material. Os balões foram colocados na capela, sob refluxo lento durante 24 horas. O extrato obtido foi filtrado a vácuo e concentrado em evaporador rotatório. Depois desse procedimento, foi mantido por sete dias em uma estufa de evaporação de solventes a $45^{\circ}$, sem ventilação. Para a triagem fitoquímica, foram colocadas pequenas porções do extrato (uma ponta de espátula) no fundo de tubos de ensaios identificados. O extrato foi inicialmente redissolvido com água, metanol, clorofórmio, éter etílico, etanol e ácido clorídrico, com agitação, baseando-se na metodologia de Matos (1997).

Após a total redissolução dos extratos nos solventes utilizados, foram realizados os testes analíticos qualitativos para caracterização dos principais grupos de substâncias vegetais de interesse, por meio de reações químicas específicas que resultaram no desenvolvimento de coloração e/ou precipitado característico. Realizaram-se os seguintes testes de identificação:

Cultura Agronômica, Ilha Solteira, v.24, n.3, p.257-274, 2015 
1) Ácidos Orgânicos: Reativo de Pascová.

2) Polissacarídeos: Lugol.

3) Taninos: Solução ácida de cloreto férrico a $1 \%$.

4) Catequinas: Solução aquosa de vanilina a $1 \%$ e ácido clorídrico concentrado.

5) Derivados de benzoquinonas, naftoquinonas e fenantraquinonas: Carbonato de sódio (25\%), formaldeído $\alpha$-dinitrobenzeno (5\%).

6) Flavonoides: Ácido clorídrico concentrado e fita de magnésio.

7) Sesquiterpenlactonas e outras lactonas: Cloridrato de hidroxilamina e solução metanólica de hidróxido de potássio $10 \%$.

8) Esteroides e triterpenoides: Reação de Liebermann-Burchard.

9) Derivados de cumarina: Teste com luz ultravioleta.

10) Saponinas espumídicas: Teste de formação de espuma.

11) Alcaloides: Reagente de Bouchardat, Dragendorff e Mayer

\section{RESULTADOS E DISCUSSÃO}

\section{Poáceas}

Os resultados das análises dos extratos das palhadas de três poáceas conduzidas em cultivo exclusivo encontram-se descritos na Tabela 1. Os testes tiveram resultados negativos para a presença de polissacarídeos, catequinas e sesquiterpenlactonas e outras lactonas para as três espécies em estudo.

Tabela 1. Substâncias presentes no extrato etanólico de três poáceas em cultivo exclusivo. UFLA, Lavras, MG, 2011.

\begin{tabular}{lccc}
\hline CONSTITUINTES & AVP & MIL & SOR \\
\hline Ácidos orgânicos & + & + & + \\
Polissacarídeos & - & - & - \\
Taninos & + & + & + \\
Catequinas & - & - & - \\
Derivados de benzoquinonas, naftoquinonas e & & & \\
fenantraquinonas & - & + & - \\
Flavonoides & + & - & - \\
Sesquiterpenlactonas e outras lactonas & - & + & - \\
Esteroides e triterpenoides & + & + & + \\
Derivados de cumarinas & + & + & + \\
Saponinas espumídicas & + & + & + \\
Alcaloides (Bouchardat) & + & + & + \\
Alcaloides (Dragendorff) & - & + & + \\
Alcaloides (Mayer) & + & +
\end{tabular}

${ }^{(1)}$ AVP - aveia-preta, MIL - milheto, SOR - sorgo. (+) positivo, (-) negativo.

Das três espécies de poáceas avaliadas, aveia-preta e sorgo são as mais estudadas no que diz respeito à produção de metabólitos secundários. Os mais conhecidos são a ordenina, pertencente ao grupo dos alcaloides, e escopoletina, que pertence ao grupo das cumarinas,

Cultura Agronômica, Ilha Solteira, v.24, n.3, p.257-274, 2015 
presentes na aveia-preta e a p-benzoquinona sorgoleone, encontrada no sorgo (ENHELLIG, 1986). Perez e Nunez (1991) identificaram, em exsudados de raízes de Avena fátua, cumarina, ácido p-hidroxibenzoico e ácido vanílico, o que indica que esses ou outros compostos possam também estar presentes em exsudados de raízes de Avena sativa ou em outras espécies de aveia.

As plantas de sorgo possuem a capacidade de exsudar aleloquímicos através dos pelos radiculares, compostos esses que também se encontram presentes nas sementes, raízes, colmos e folhas em quantidades variáveis (PEIXOTO; SOUZA, 2002), interferindo no manejo das plantas cultivadas e daninhas (SANTOS, 1996). Essas substâncias orgânicas são responsáveis por uma grande diversidade de efeitos nas plantas, tais como o atraso ou a inibição completa da germinação de sementes, paralisação do crescimento, injúria no sistema radicular, clorose, murcha e morte das plantas (RICE, 1984). Guenzi e McCalla (1966) isolaram quantidades substanciais de ácido ferúlico, vanílico, siríngico, e phidroxibenzoico de resíduos de sorgo. Lehle e Putnam (1983) também isolaram tais ácidos, além de outros, e mostraram ação inibitória de várias frações químicas separadas.

A presença de ácidos orgânicos foi observada nos extratos dos resíduos de aveia-preta, milheto e sorgo e, de acordo com Einhellig (1986), ácidos orgânicos resultantes da decomposição de resíduos no solo interferem na absorção de nutrientes, retardando o desenvolvimento da planta.

Os testes revelaram a presença de taninos nos extratos das três espécies. Em termos agronômicos, a importância dos taninos vegetais sintetizados pelas plantas ocorre pela sua efetividade como repelente a predadores, animais e micro-organismos. Almeida (1985) observou que os taninos adicionados ao solo em contato com a planta inibiram a ação de giberelinas em plântulas de ervilha.

A presença de derivados de benzoquinonas, naftoquinonas e fenantraquinonas foi detectada apenas no extrato preparado com a palha de sorgo. Einhelling et al. (1993) afirmam que o controle de plantas espontâneas pelos efeitos alelopáticos do sorgo ocorre como resultado da presença de glicosídeos cianogênicos, taninos, flavonoides, ácidos fenólicos e a p-benzoquinona sorgoleone. Esse metabólito secundário é um potente inibidor da respiração mitocondrial e também do transporte de elétrons do fotossistema II, atuando competitivamente no mesmo local de ação de herbicidas, como atrazine e diuron (Gonzalez et al., 1997). Em experimentos conduzidos em laboratório e casa de vegetação, sorgoleone inibiu o desenvolvimento de espécies como Eragrotis tef, Lactuca sativa, Lemma minor e Amaranthus retroflexus (NIMBAL et al., 1996).

Nos extratos de aveia-preta e milheto, foi detectada a presença de flavonoides, que são moléculas solúveis em água contendo 15 átomos de carbono. Pertencem à família dos polifenóis e são formados por seis subgrupos principais: chalconas, flavonas, flavonóis, flavanonas, antocianinas e isoflavonoides. Junto com carotenos, os flavonoides são também responsáveis pela coloração de frutas, legumes e ervas. Além disso, alguns flavonoides têm atividade inibitória contra organismos que causam doenças na planta, como por exemplo, Fusarium oxysporum (SIQUEIRA et al., 1991). 
A reação positiva com anidrido acético e ácido sulfúrico evidenciou a presença de esteroides e triterpenoides nos extratos oriundos das palhadas de aveia-preta e milheto. Os esteroides são componentes comuns nos vegetais. Esses compostos estão envolvidos no crescimento do tubo polínico, na elongação do entrenó, enrolamento de folhas de poáceas e são considerados reguladores de crescimento (BUCHANAN et al., 2000). Alguns esteroides foram isolados de cereais com atividade alelopática, como em cevada (Hordeum vulgare) (EVERALL; LEES, 1996) e trigo (Triticum aestivum) (TANAKA et al., 1990).

Constatou-se a presença de cumarinas nos extratos analisados. Os compostos fenólicos constituem o mais extensivamente estudado e conhecido grupo de aleloquímicos com respeito ao seu modo de ação. A literatura disponível é mais detalhada que para qualquer outro grupo de compostos alelopáticos. Einhellig (2004) cita que ácidos fenólicos simples, cumarinas e taninos parecem ter modos semelhantes de ação que afetam o crescimento de plantas e micróbios por efeitos fisiológicos múltiplos, que conferem a eles uma toxicidade geral. Devido à sua natureza aromática, a maioria deles interfere em processos onde o fluxo de carga (elétron ou cátions) está presente, como por exemplo, nos processos fotossintéticos, defletores de elétrons, inibidores ou competidores do sistema PSII, transporte de íon de membrana e permeabilidade. A ação alelopática da aveia-preta é atribuída principalmente à sua capacidade de exsudar escopoletina. A escopoletina é um metabólito secundário da classe das cumarinas e tem efeito inibidor do crescimento radicular das plantas (MONTEIRO; VIEIRA, 2002). Jacobi e Fleck (2000) encontraram que a escopoletina inibiu o crescimento radicular da raiz e parte aérea de azevém.

A presença de saponinas também foi confirmada nos extratos das três poáceas em estudo. As saponinas, ou saponosídeos, são heterosídeos do metabolismo secundário vegetal. Essas moléculas são sintetizadas do ácido mevalônico, via rota do isoprenoide e são derivadas da ciclisação de triterpenoides ou de esteroides. São caracterizadas por suas propriedades surfactantes (o nome saponina é derivado de sapo, palavra latina para sabão), ou seja, pela formação de espuma, tendo ainda propriedades detergentes. São compostos formados por uma parte hidrofílica e uma parte lipofílica. Em meio aquoso, as saponinas são afrogênicas e, sendo assim, possuem uma elevada solubilidade em água. Já em solventes orgânicos apolares é insolúvel. Elas apresentam sabor acre e amargo e podem causar efeitos alelopáticos pela desorganização de membranas celulares (OSBOURN, 2003).

A presença de alcaloides foi confirmada nos extratos das três espécies avaliadas. Os alcaloides são compostos químicos naturais, de origem vegetal, derivados de bases orgânicas nitrogenadas. São geralmente substâncias cristalinas, incolores, não voláteis, de gosto amargo, insolúveis em água e solúveis em solventes orgânicos. Alguns são líquidos e solúveis em água, como a coniina e a nicotina. Segundo Wink e Latz-Bruning (1995), encontram-se alcaloides em apocináceas, papaveráceas, papilionáceas, ranunculáceas e rubiáceas. Os alcaloides mais simples ocorrem, frequentemente, em plantas muito diversas, mesmo sem afinidade botânica, ao passo que os mais complexos (nicotina, cocaína, quinina, etc.) limitam-se a uma dada espécie, que lhes serve, por vezes, como caráter distintivo. Uma espécie raramente contém apenas um alcaloide.

Cultura Agronômica, Ilha Solteira, v.24, n.3, p.257-274, 2015 


\section{Crotalária}

Os resultados das análises dos extratos das palhadas de crotalária em cultivo exclusivo e consorciada com três poáceas encontram-se na Tabela 2. Os testes foram negativos, indicando ausência de polissacarídeos e catequinas para todos os extratos estudados.

Tabela 2. Substâncias presentes em extrato etanólico de Crotalaria anagyroides em cultivo exclusivo e consorciada com três poáceas. UFLA, Lavras, MG, 2011.

\begin{tabular}{lcccc}
\hline CONSTITUINTES & $\mathrm{CRO}^{(1)}$ & $\mathrm{CRO}+\mathrm{AVP}$ & $\mathrm{CRO}+\mathrm{MIL}$ & $\mathrm{CRO}+\mathrm{SOR}$ \\
\hline Ácidos orgânicos & + & + & + & + \\
Polissacarídeos & - & - & - & - \\
Taninos & + & - & + & + \\
Catequinas & - & - & - & - \\
Derivados de benzoquinonas, & & & - & + \\
naftoquinonas e fenantraquinonas & - & - & - & + \\
Flavonoides & - & + & - & - \\
Sesquiterpenlactonas e outras & & & - & + \\
lactonas & - & + & + & + \\
Esteroides e triterpenoides & + & + & + & + \\
Derivados de cumarinas & + & + & + & + \\
Saponinas espumídicas & + & + & + & - \\
Alcaloides (Bouchardat) & + & + & - & \\
Alcaloides (Dragendorff) & - & - & - & \\
Alcaloides (Mayer) & - & - & + & \\
(1) CRO - crotalária, AVP - aveia-preta, MIL - milheto, SOR - sorgo. (+) positivo, (-) negativo. &
\end{tabular}

A presença de ácidos orgânicos, observada anteriormente nos extratos de aveia-preta, milheto e sorgo (Tabela 1) ficou também evidenciada nos consórcios dessas poáceas com crotalária, bem como no seu extrato quando em cultivo exclusivo (Tabela 2).

Os taninos encontrados nos extratos das três poáceas em cultivo exclusivo tiveram presença confirmada quando milheto e sorgo foram consorciados com crotalária. Apesar de a crotalária apresentar resultado positivo para taninos em cultivo exclusivo, quando consorciada com aveia-preta apresentou resultado negativo, indicando ausência desse metabólito no extrato.

Derivados de benzoquinonas, naftoquinonas e fenantraquinonas foram detectados somente no extrato de crotalária consorciada com sorgo (Tabela 2), provavelmente pela presença desses compostos na palha da poácea (Tabela 1).

A presença de flavonoides não foi observada no extrato da palhada de crotalária, quando em cultivo exclusivo (Tabela 2). Quando consorciada com aveia-preta, houve confirmação do composto no extrato, corroborando o resultado encontrado no teste da poácea em cultivo exclusivo (Tabela 1). No extrato preparado com a palha oriunda do consórcio entre a leguminosa e milheto, o resultado foi negativo, apesar de ser positivo para a poácea em cultivo exclusivo. Os extratos das palhas de crotalária e sorgo apresentarem reação negativa para flavonoides, quando em cultivo exclusivo; contudo, o extrato de seu 
consórcio teve reação positiva, indicando a presença do composto. Segundo Globo-Neto e Lopes (2007), a produção de metabólitos secundários representa a interface química entre as plantas e o meio ambiente circundante; portanto, sua síntese é frequentemente afetada por condições ambientais, tais como sazonalidade, índice pluviométrico, temperatura e altitude, entre outros. Logo, a proximidade de uma planta com outra também pode afetar a produção dos metabólitos, devido à competição por água, luz e nutrientes.

Resultado semelhante foi encontrado com os testes realizados para detecção de sesquiterpenlactonas e outras lactonas. O resultado foi negativo para os extratos das três poáceas e também para a crotalária em cultivo exclusivo. Ausência desses compostos também foi verificada nos extratos originários das palhas dos consócios entre a leguminosa e milheto e sorgo; porém, para o consórcio entre crotalária e aveia-preta, o resultado foi positivo.

O extrato originado da palha de crotalária em cultivo exclusivo teve reação positiva para esteroides e triterpenoides. Resultado semelhante foi encontrado quando a abordagem foi realizada no extrato de crotalária consorciada com aveia-preta e sorgo. Apesar de ter sido confirmada a presença de esteroides e triterpenoides nos extratos de crotalária e milheto em cultivo exclusivo, o teste realizado no extrato proveniente da palha do consórcio entre as duas espécies apresentou resultado negativo. Os triterpenoides são metabólitos secundários relacionados a intensas atividades biológicas. Conforme mencionado por Fischer (1994), junto com monoterpenos e sesquiterpenos, são os terpenoides mais envolvidos em alelopatia. No trabalho realizado por Matos et al. (1995) com extrato hidroalcoólico de Crotalária juncea, o resultado foi positivo para esteroides, mas não foram encontrados triterpenoides no material analisado.

A presença de derivados de cumarinas e saponinas espumídicas, foi confirmada nos testes realizados para os extratos de crotalária em cultivo exclusivo e consorciada com aveia-preta, milheto e sorgo (Tabela 2). Esses resultados ratificam os encontrados para as três poáceas cultivadas em cultivo exclusivo (Tabela 1).

A reação positiva com o reagente de Bouchardat indicou a presença de alcaloides nos extratos de crotalária em cultivo exclusivo e consorciada com aveia-preta, milheto e sorgo (Tabela 2). O mesmo resultado foi obtido quando analisados os extratos das três poáceas em cultivo exclusivo (Tabela 1). De acordo com Huxtable (1990), plantas do gênero Crotalaria são ricas em alcaloides pirrolizidínicos, que constituem um grande grupo de moléculas de caráter básico que contêm nitrogênio em sua estrutura, normalmente formando um anel heterocíclico, o núcleo pirrolizidínico, sendo amplamente disseminados, tanto geograficamente quanto botanicamente (PRAKASH et al., 1999). A monocrotalina (MCT) é o principal alcaloide pirrolizidínico encontrado nas plantas do gênero Crotalaria e é considerado um metabólito secundário com funções alelopáticas (FASSULIOTIS; SKUCAS, 1969).

\section{Feijão-de-porco}

Os resultados dos testes para os extratos das palhadas de feijão-de-porco em cultivo 
exclusivo e consorciado com três poáceas encontram-se na Tabela 3. Os testes foram negativos, indicando ausência de polissacarídeos; catequinas; derivados de benzoquinonas, naftoquinonas e fenantraquinonas; sesquiterpenlactonas e outras lactonas para todos os testes realizados.

A presença de ácidos orgânicos observada anteriormente nos extratos das três poáceas (Tabela 1) confirmou-se apenas nos consórcios entre aveia-preta e milheto com feijão-deporco, bem como no extrato da leguminosa em cultivo exclusivo.

$\mathrm{O}$ extrato obtido com a palha de feijão-de-porco em cultivo exclusivo proporcionou reação positiva para taninos. A presença de taninos em extrato hidroalcoólico de feijão-deporco também foi confirmada no trabalho de Matos et al. (1995). Resultado semelhante foi encontrado para os extratos feitos com as palhas de seu consórcio com aveia-preta, milheto e sorgo (Tabela 3) e para os extratos das três poáceas em cultivo exclusivo (Tabela 1). Dentre os compostos polares, os fenólicos e derivados correspondem à classe de metabólitos secundários na qual se encontra a maior parte dos compostos apontados como tendo atividade alelopática, compreendendo desde fenóis simples até taninos de estrutura complexa (Rice, 1984).

Tabela 3. Substâncias presentes em extrato etanólico de Canavalia ensiformis em cultivo exclusivo e consorciado com três poáceas. UFLA, Lavras, MG, 2011.

\begin{tabular}{|c|c|c|c|c|}
\hline CONSTITUINTES & $\mathrm{FDP}^{(1)}$ & $\mathrm{FDP}+\mathrm{AVP}$ & FDP + MIL & $\mathrm{FDP}+\mathrm{SOR}$ \\
\hline Ácidos orgânicos & + & + & + & - \\
\hline Polissacarídeos & - & - & - & - \\
\hline Taninos & + & + & + & + \\
\hline Catequinas & - & - & - & - \\
\hline $\begin{array}{l}\text { Derivados de benzoquinonas, } \\
\text { naftoquinonas e fenantraquinonas }\end{array}$ & - & - & - & - \\
\hline Flavonoides & - & - & + & - \\
\hline Sesquiterpenlactonas e outras & & & & \\
\hline lactonas & - & - & - & - \\
\hline Esteroides e triterpenoides & + & - & + & - \\
\hline Derivados de cumarinas & + & + & + & + \\
\hline Saponinas espumídicas & + & + & + & + \\
\hline Alcaloides (Bouchardat) & + & + & + & - \\
\hline Alcaloides (Dragendorff) & + & - & + & - \\
\hline Alcaloides (Mayer) & - & - & + & - \\
\hline
\end{tabular}

${ }^{(1)} \mathrm{FDP}$ - feijão-de-porco, AVP - aveia-preta, MIL - milheto, SOR - sorgo. (+) positivo, (-) negativo.

A presença de flavonoides não foi verificada no extrato de feijão-de-porco em cultivo exclusivo. Apesar de o extrato elaborado com a palha de aveia-preta em cultivo exclusivo mostrar reação positiva para esses compostos, no seu consórcio com feijão-de-porco a reação foi negativa, como também foi para o consórcio entre feijão-de-porco e sorgo. Somente o consórcio entre a leguminosa e o milheto apresentou extrato cuja presença de flavonoides foi confirmada. 
Para o extrato da palha de feijão-de-porco em cultivo exclusivo, os resultados foram positivos para esteroides e triterpenoides. Matos et al. (1995), analisando o extrato hidroalcoólico de feijão-de-porco, encontraram resultado positivo para esteroides, mas não foram encontrados triterpenoides no material analisado. Resultado positivo também foi encontrado para o extrato feito com a palha de feijão-de-porco consorciado com milheto. Os extratos confeccionados com as palhas de feijão-de-porco em cultivo exclusivo e aveia-preta em cultivo exclusivo apresentaram reação positiva para a presença de esteroides e triterpenoides; porém, esses metabólitos não foram detectados no extrato proveniente do consórcio entre as duas espécies.

A presença de derivados de cumarinas e saponinas espumídicas, foi confirmada nos testes realizados para os extratos de feijão-de-porco em cultivo exclusivo e consorciado com aveia-preta, milheto e sorgo (Tabela 3). Esses resultados corroboram os encontrados para as três poáceas cultivadas em cultivo exclusivo (Tabela 1).

A presença de alcaloides não foi observada no extrato procedente do consórcio entre feijão-de-porco e sorgo. Os metabólitos foram detectados com a adição do Reativo de Bouchadart nos extratos feitos com as palhas de feijão-de-porco em cultivo exclusivo e consorciado com aveia-preta e milheto. Com a adição do Reativo de Dragendorff, a presença de alcaloides foi confirmada nos extratos de feijão-de-porco em cultivo exclusivo e consorciado com milheto. Já com a adição do Reativo de Mayer, a presença de alcaloides foi comprovada apenas no extrato feito com a palha do consórcio entre feijão-de-porco e milheto.

\section{Guandu}

Os resultados das análises dos extratos das palhadas de guandu em cultivo exclusivo e consorciado com aveia-preta, milheto e sorgo encontram-se na Tabela 4. Os testes foram negativos, indicando ausência de polissacarídeos, catequinas e derivados de benzoquinonas, naftoquinonas e fenantraquinonas para todos os testes realizados.

Testes realizados com os extratos de guandu em cultivo exclusivo e consorciado com aveia-preta, milheto e sorgo confirmaram a presença de taninos e saponinas espumídicas. Esses resultados estão de acordo com os encontrados para as três poáceas cultivadas em cultivo exclusivo (Tabela 1).

A presença de ácidos orgânicos observada anteriormente nos extratos de aveia-preta, milheto e sorgo em cultivo exclusivo (Tabela 1) ficou também evidenciada nos consórcios dessas poáceas com guandu, embora a presença desses metabólitos não tenha sido observada no extrato feito com a leguminosa em cultivo exclusivo (Tabela 4).

O teste para detecção de flavonoides foi negativo para o extrato de guandu em cultivo exclusivo e positivo para os extratos provenientes do consórcio entre essa leguminosa e aveia-preta, milheto e sorgo (Tabela 4), todavia, a presença de flavonoides no extrato oriundo da palha de sorgo em cultivo exclusivo não foi confirmada (Tabela 1). Os flavonoides são outro exemplo da ação indireta de metabólitos secundários nos organismos, causando efeitos alelopáticos benéficos para as plantas. Flavonoides secretados pela raiz da

Cultura Agronômica, Ilha Solteira, v.24, n.3, p.257-274, 2015 
planta hospedeira beneficiam o Rhizobium no estágio de infecção de sua relação simbiótica com espécies da família das leguminosas como ervilha, feijão e soja. A presença desses flavonoides faz com que o Rhizobium, que vive no solo, ative os fatores de secreção de nodulação, que em troca são reconhecidos pela planta anfitriã, levando à deformação os pelos radiculares e várias respostas celulares, como fluxos de íon, culminando com a formação dos nódulos na raiz (GRAHAM, 1991).

Tabela 4. Substâncias presentes em extrato etanólico de Cajanus cajan em cultivo exclusivo e consorciada com três poáceas. UFLA, Lavras, MG, 2011.

\begin{tabular}{lcccc}
\hline CONSTITUINTES & GUA $^{(1)}$ & GUA + AVP & GUA + MIL & GUA + SOR \\
\hline Ácidos orgânicos & - & + & + & + \\
Polissacarídeos & - & - & - & - \\
Taninos & + & + & + & + \\
Catequinas & - & - & - & - \\
Derivados de benzoquinonas, & & & & \\
naftoquinonas e fenantraquinonas & - & - & - & + \\
Flavonoides & - & + & + & + \\
Sesquiterpenlactonas e outras & & & & + \\
lactonas & - & + & + & + \\
Esteroides e triterpenoides & - & + & + & + \\
Derivados de cumarinas & + & + & - & + \\
Saponinas espumídicas & + & + & + & + \\
Alcaloides (Bouchardat) & - & + & + & + \\
Alcaloides (Dragendorff) & + & - & + & + \\
Alcaloides (Mayer) & - & - & - & + \\
\hline
\end{tabular}

${ }^{(1)} \mathrm{GUA}$ - guandu, AVP - aveia-preta, MIL - milheto, SOR - sorgo. (+) positivo, (-) negativo.

Sesquiterpenlactonas e outras lactonas foram encontradas apenas nos extratos provenientes das palhas de guandu consorciado com as três poáceas (Tabela 4), apesar de não serem encontradas na palha de guandu, aveia-preta, milheto e sorgo em cultivo exclusivo (Tabela 1). Sesquiterpenlactonas são metabólitos secundários com propriedades alelopáticas. Um exemplo de lactona sesquiterpênica com atividade biológica é a guaianolida. Essa sesquiterpenlactona foi citada como agente alelopático por Macías et al. (2005), especialmente na família das Compositae, apresentando grande fitotoxicidade. O autor ressalta a importância da estrutura da molécula e a lipofilia, que é o fator chave na absorção de alguns compostos bioativos, como determinantes na biodisponibilidade na célula. A guaianolida apresentou uma boa propriedade lipofílica, indicando-a como promissora para a criação de novos herbicidas.

O extrato obtido com a palha de guandu em cultivo exclusivo apresentou reação negativa para a esteroides e triterpenoides (Tabela 4). Os extratos confeccionados com as palhas do consórcio entre a leguminosa e aveia-preta e milheto tiveram reação positiva. Esses resultados estão de acordo com os obtidos nos testes realizados para os extratos das palhas das poáceas em cultivo exclusivo (Tabela 1). De acordo com Castro (2001), os terpenoides desempenham funções hormonais, são inibidores do crescimento e de 
pigmentos, constituintes da cadeia de transporte de elétrons e atuam também no transporte de moléculas através da membrana. Por outro lado, os esteroides são importantes componentes de membranas, onde eles estabilizam as caudas dos fosfolipídios, podendo também funcionar como hormônios, tais como um grupo de derivados esteroides chamados brassinas, que promovem o crescimento de certos caules.

A presença de derivados de cumarinas observada anteriormente nos extratos de aveiapreta, milheto e sorgo (Tabela 1) ficou evidenciada nos consórcios de guandu com aveiapreta e sorgo, bem como no seu extrato quando em cultivo exclusivo (Tabela 4).

A presença de alcaloides nos extratos de guandu em cultivo exclusivo e nos extratos provenientes de seu consórcio com aveia-preta, milheto e sorgo foi confirmada pelos testes de Bouchardat e Dragendorff (Tabela 4), corroborando os resultados encontrados para os testes realizados com os extratos das três poáceas em cultivo exclusivo (Tabela 1).

\section{CONCLUSÃO}

- Derivados de cumarinas e saponinas espumídicas, são compostos encontrados em todas as espécies de adubos verdes estudadas, tanto em cultivo exclusivo como em consórcio.

- Ácidos orgânicos estão presentes em todas as espécies de adubos verdes em cultivo exclusivo, exceto guandu e ausentes apenas no consórcio feijão-de-porco + sorgo.

- Taninos estão presentes em todas as espécies de adubos verdes em cultivo exclusivo e ausentes apenas no consórcio crotalária + aveia-preta.

- Flavonoides estão presentes nos resíduos de aveia-preta e milheto e ausentes em todas as leguminosas em cultivo exclusivo. Estão ainda presentes em todos os consórcios, exceto crotalária + milheto, feijão-de-porco + aveia-preta, feijão-de-porco + sorgo.

- Esteroides e triterpenoides estão presentes nos resíduos de crotalária, feijão-deporco, aveia-preta e milheto em cultivo exclusivo. Estão presentes nos consórcios crotalária + aveia-preta, crotalária + sorgo, feijão-de-porco + milheto, guandu + aveia-preta e guandu + milheto.

- Derivados de cumarinas estão presentes nos extratos de todas as palhas testadas, exceto no proveniente do consórcio entre guandu + milheto.

- Alcaloides estão presentes em todas as espécies de adubos verdes em cultivo exclusivo e ausentes apenas no consórcio feijão-de-porco + sorgo.

\section{REFERÊNCIAS BIBLIOGRÁFICAS}

ALMEIDA, F. S. Plantio direto: efeitos alelopáticos das coberturas mortas. Informe Agropecuário, Belo Horizonte, v. 11, n. 129, p.44-64, 1985.

Cultura Agronômica, Ilha Solteira, v.24, n.3, p.257-274, 2015 
AMABILE, R. F.; CARVALHO, A. M. Histórico da adubação verde. In: CARVALHO, A. M.; AMABILE, R. F. (Ed.). Cerrado: adubação verde. Planaltina: Embrapa Cerrados, 2006. cap. 1, p.23-37.

BUCHANAN, B.; GRUISSEM, W.; JONES, R. Biochemistry and molecular biology of plants. Rochville: American Society of Plant Physiologists, 2000. 419 p.

CAStro, H. G. Contribuição ao estudo das plantas medicinais: metabólitos secundários. Visconde do Rio Branco: Suprema, 2001. 104 p.

CHERR, C. M.; SCHOLBERG, J. M. S.; MCSORLEY, R. Green manure approaches to crop production: a synthesis. Agronomy Journal, Madison, v. 98, n. 2, p.302-319, 2006.

CHOU, C. H. Roles of allelopathy in plant biodiversity and sustainable agriculture. Critical Reviews in Plant Sciences, Boca Raton, v. 18, n. 5, p.609-630, 1999.

EMPRESA BRASILEIRA DE PESQUISA AGROPECUÁRIA. Sistema brasileiro de classificação de solos. 2. ed. Brasília: Embrapa Informação Tecnológica, 2000. 412 p.

EINHELLIG, F. A. Effects of allelopathic chemicals on crop productivity. In: HEDIN, P. (Ed.). Bioregulators for pest control. Washington: American Chemical Society, 1985. cap. 5, p. 109-130.

EINHELLIG, F. A. Mechanisms and modes of action of allelochemicals. In: PUTNAM, A. R.; TANG, C. (Ed.). The science of allelopathy. New York: John Wiley e Sons, 1986. cap. 10, p. $171-188$.

EINHELlinG, F. A.; RASMUSSEN, J. A.; HEJL, A. M.; SOUZA, I. F. Effect of root exudates sorgoleone on photosynthesis. Journal of Chemical Ecology, New York, v. 19, n. 2, p.369-375, 1993.

EINHELLIG, F. A. Mode of allelochemical action of phenolic compounds. In: MACÍAS, F. A.; GAlindo, J. C. G.; MOLinillo, J. M. G. V.; CUTLER, H. G. (Ed.) Allelopathy: chemistry and mode of action. Boca Raton: CRC Press, 2004. cap. 7, p. 217-238.

EVERALL, N.; LEES, D. The use of barley-straw to control general and blue-green algal growth in a derbyshire reservoir. Water Research, Amsterdam, v. 30, n. 2, p.269-276, 1996.

FASSULIOTIS, G.; SKUCAS, G. P. The effect of pyrrolizidine alkaloid ester and plants containing pyrrolizidine on Meloidogyne incognita acrita. Journal of Nematology, New Delhi, v. 1, p.287-288, 1969.

Cultura Agronômica, Ilha Solteira, v.24, n.3, p.257-274, 2015 
FERREIRA, A. G.; ÁQÜILA, M. E. A. Alelopatia: uma área emergente da ecofisiologia. Revista Brasileira de Fisiologia Vegetal, Brasília, v. 12, Edição Especial , p.175-204, 2000.

FISCHER, N. H. Research of allelopathy in the Florida scrubs: the role of terpenoids. Journal of Chemical Ecololgy, New York, v. 20, n. 6, p.1355-1358, 1994.

GLOBO-NETO, L.; LOPES, N. P. Plantas medicinais: fatores de influência no conteúdo de metabólitos secundários. Química Nova, São Paulo, v. 30, n. 2, p.374-381, 2007.

GOMES JÚNIOR, F. G.; CHRISTOFFOLETI, P. J. Biologia e manejo de plantas daninhas em áreas de plantio direto. Planta Daninha, Viçosa, v. 26, n. 4, p.103-108, 2008.

GONZALEZ, V. M. KAZIMIR, J.; NIMBAL. C.; WESTON, L.; CHENIAE, G. M. Inhibition of a photosystem II eletron transfer reaction by the natural product sorgoleone. Journal of Agricultural and Food Chemistry, Eanston, v. 45, n. 4, p.1415-1421, 1997.

GRAHAM, T. L. Flavonoid and isoflavonoid distribution in developing soybean seedling tissues and in seed and root exsudates. Plant Physiology, Lancaster, v. 95, n. 2, p.594-603, 1991.

GUENZI, W. D.; McCALLA, T. M. Phenolic acids in oats, wheat, sorghum, and corn residues and their phytotoxicity. Agronomy Journal, Madison, v. 58, n. 2, p.303-304, 1966.

HUXTABLE, R. J. Activation and toxicity of pyrrolizidine alkaloids. Pharmacology e Therapeutics, Saint Louis, v. 47, n. 5, p.371-385, 1990.

JACOBI, U. S.; FLECK, N. G. Avaliação do potencial alelopático de genótipo de aveia no início do ciclo. Pesquisa Agropecuária Brasileira, Brasília, v. 35, n. 1, p.11-19, 2000.

LEHLE, F. R.; PUTNAM, A. R. Allelopathic potential of sorghum (Sorghum bicolor): isolation of seed germination inhibitors. Journal of Chemical Ecology, New York, v. 9, n. 8, p.1223-1234, 1983.

MACÍAS, F. A; VELASCO, R.; CASTELLANO, D.; GALINDO, J. Aplication of Hansch's model to guaianolide Ester derivatives: a quantitative estructure -activity relationship study. Journal of Agriculture and Food Chemistry, Eanston, v. 53, n. 9, p.3530-3539, 2005.

MATHEIS, H. A. S. M.; AZEVEDO, F. A.; VICTÓRIA FILHO, R. Adubação verde no manejo de plantas daninhas na cultura de citros. Laranja, Cordeirópolis, v. 17, n. 1, p.101110, 2006.

Cultura Agronômica, Ilha Solteira, v.24, n.3, p.257-274, 2015 
MATOS, F. J. A. Roteiro sequencial de prospecção de constituintes químicos de extratos de plantas. In: MATOS, F.J.A. (Ed.). Introdução a fitoquímica experimental. Fortaleza: UFC, 1997. cap. 4, p.41-75.

MATOS, A. S. V.; PESSANHA, G. G.; CARVAlHO, M. G.; BRAZ FILHO, R. Identificação de substâncias secundárias presentes em leguminosas utilizadas como adubo verde. Revista Ceres, Viçosa, v. 42, n. 244, p.584-598, 1995.

MONTEIRO, C. A.; VIEIRA, E. Substâncias alelopáticas. In: CASTRO, P. R. C.; SENA, J. O. A; KLUGE, R. A. Introdução à fisiologia do desenvolvimento vegetal. Maringá: Universidade Estadual de Maringá, 2002. cap. 2, p.105-122.

NIMBAL, C. I.; PEDERSON, J.; YERKES, C. N.; WESTON, L.; WELLER, S. C. Phytotoxicity and distribution of sorgoleone in grain sorghum germplasm. Journal of Agricultural and Food Chemistry, Eanston, v. 44, n. 5, p.1343-1347, 1996.

OSBOURN, A. R. E. Saponins in cereals. Phytochemistry, New York, v. 62, n. 1, p.1-4, 2003.

PEIXOTO, M. F.; SOUZA, I. F. Efeitos de doses de imazamox e densidades de sorgo (Sorghum bicolor (L.) Moench) em soja (Glycine Max (L.) Merril) sob plantio direto. Ciência e Agrotecnologia, Lavras, v. 26, n. 2, p.252-258, 2002.

PEREZ, F. J.; NUNEZ, J. O. Root exudates of wild oats. Allelopathic effect on spring wheat. Phytochemistry, New York, v. 30, n. 7, p.2199-2202, 1991.

PRAKASH, A. S.; PEREIRA, T. N.; REILlY P. E.; SEAWRIGHT, A. A. Pyrrolizidine alkaloids in human diet. Mutation Research, Amsterdam, v. 5, n. 1, p.53-67, 1999.

PUTNAM, A. R.; TANG, C. S. The science of allelopathy. New York: John Wiley e Sons, 1986. $235 \mathrm{p}$.

RICE, E. L. Allelopathy. 2.ed. Orlando : Academic Press, 1984. 422 p.

ROSSI, C. Q.; ALVES, R. E. A.; FERNANDES, P. R. T.; PEREIRA, M. G.; RIBEIRO, R. L. D. Liberação de macronutrientes de resíduos do consórcio entre mucuna preta e milho sob sistema orgânico de produção. Revista de Ciências da Vida, Seropédica, v. 28, n. 2, p.1-10, 2008.

SANTOS, O. G. Alelopatia de genótipos de sorgo (Sorghum bicolor) em sistemas de cultivos de hortaliças. 1996. 27 f. Dissertação (Mestrado em Agronomia) - Universidade de Brasília, Brasília, 1996.

Cultura Agronômica, Ilha Solteira, v.24, n.3, p.257-274, 2015 
SIQUEIRA, J. O.; NAIR, M. G.; HAMMERSCHIMIDT, R.; SAFIR, G. R. Significance of phenolic compounds in plant-soil-microbial systems. Critical Review in Plant Science, Boca Raton, v. 10, n. 1, p.63-121, 1991.

TANAKA, F.; ONO, S.; HAYASAKA, T. Identification and evaluation of toxicity of rice root elongation inhibitors in flooded soils whit added wheat straw. Soil Science e Plant Nutrition, Tokyo, v. 36, n. 1, p.97-103, 1990.

TEASDALE, J. R. Cover crops, smother plants, and weed management. New York: Arbor Press, 1998. 350 p.

WINK, R.; LATZ-BRUNING, J. Allelopathic properties of alkaloids and other natural products. Symposium Series, Washingon, v. 582, n. 1, p.117-126, 1995. 
